International Journal of Advances in Pharmacy and Biotechnology

Vol.4, Issue-4, 2018, 1-5

Research Article

Open Access.

I J A P B

ISSN: $2454-8375$

\title{
PHENYTOIN INDUCED TOXIC EPIDERMAL NECROLYSIS - A CASE REPORT
}

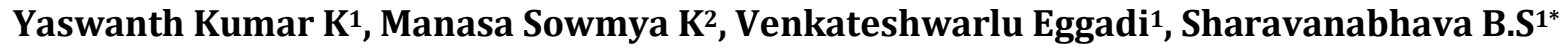

${ }^{1}$ Department of Clinical Pharmacy \& Pharm.D., Vaagdevi College of Pharmacy, Warangal, Telangana, Kakatiya University- 506001, India.

${ }^{2}$ Manisha Neuropsychiatry Clinic, Kakaji Colony, Hanamkonda, Warangal-506007, Telangana, India. Institute of Pharmaceutical Sciences, Visakhapatnam-531173, A.P., India.

*Corresponding author e-mail: sharvanabhava6@gmail.com

\begin{abstract}
:
Toxic Epidermal Necrolysis (TEN) is a rare but severe life-threatening skin disorder characterized by fever, headache and mucocutaneous lesion leading to necrolysis and detachment of full thickness of epidermis with sloughing, generally precipitated by drugs. A 68 years old male patient was admitted to hospital with a history of high-grade fever, headache and blurred vision. For his present illness he used Phenytoin. He was apparently asymptomatic for 5 days then patient presented with brownish-black discoloration of skin and rash all over the body. Nikolsky's sign was positive. Referral from a dermatologist confirmed the diagnosis of Toxic Epidermal Necrolysis. Before starting treatment with anticonvulsants and other drugs that cause adverse reactions, patients are to be screened so that further complications and mortality can be reduced.
\end{abstract}

Key words: Toxic Epidermal Necrolysis (TEN), Phenytoin, Nikolsky's signs, Anticonvulsants

\section{INTRODUCTION:}

Toxic Epidermal Necrolysis (TEN) also known as Lyell's syndrome is a rare but severe lifethreatening skin disorder characterized by fever, headache and mucocutaneous lesion leading to necrolysis and detachment of full thickness of epidermis with sloughing generally precipitated by drugs [1]. Early sites of cutaneous involvement are the presternal region of the trunk, face, palms and soles. Association (erythema and erosions) of the buccal, genital and/or ocular mucosa occurs in more than $90 \%$ of patients, and in some cases the respiratory and gastrointestinal tracts are also affected [2, 3].

TEN often involves detachment of more than $30 \%$ of the total body surface area where as Steven-Johnson syndrome (SJS) involves detachment of $10 \%$ or less body surface area.
An overlap of SJS-TEN for cases with between $10 \%$ and $30 \%$ body surface area [4].

The annual risk incidence is approximately one case per million people for TEN [5]. The mortality rate varies from 25 to $80 \%[6,7]$. The most common medications associated with TEN are: anticonvulsants (Phenytoin, Carbamazepine, Sodium Valporate, Phenobarbitone) 35.1\%, antibiotics (ATT, Ampicillin-Cloxacillin, Sulfonamides) 33.3\% and Non-Steroid Anti-inflammatory Drugs (Paracetamol, Nimesulide) 24.6\% [8].

\section{CASE REPORT}

A 68 years old male patient was admitted to Mahatma Gandhi Memorial Hospital (MGMH), Warangal, Telangana, India, with a history of high-grade fever, headache and blurred vision. He was a known case of epilepsy, but on irregular medication. 
Initial examination revealed the patient conscious and coherent with the Pulse 68 beats/min, B.P - 220/120 mmHg, Heart S1S2+, Lungs - clear. The bio-chemical profile was Blood urea $46 \mathrm{mg} \%$, Random 75mg\%, Serum Creatinine $2.3 \mathrm{mg} \%$, potassium 3.4 mmol/lit, Sodium $143 \mathrm{mmol} / \mathrm{lit}$, Chloride 110 mmol/lit and Creatinine Kinase MB 35IU/L, Creatine Kinase 15U/L. The 2D ECHO revealed concentric Left ventricular hypertrophy (LVH), mild aortic regurgitation (AR) and mild tricuspid regurgitation (TR).

He was diagnosed as concentric LVH with accelerated hypertension with Acute kidney injury. Initially tablet Phenytoin (100mg) and anti-hypertensives (including injection Furosemide 20mg BID) were prescribed.

He was apparently asymptomatic for 5 days but presented with brownish-black discoloration of skin and rashes all over the body. Rash was more on the back (figure 1). Within the next day, he developed erosions on back (figure 3), penis, oral cavity with red mucosa, tongue is also erythematous (figure 2). Blisters are seen on buttock and all over the body. Nikolsky's sign was positive.

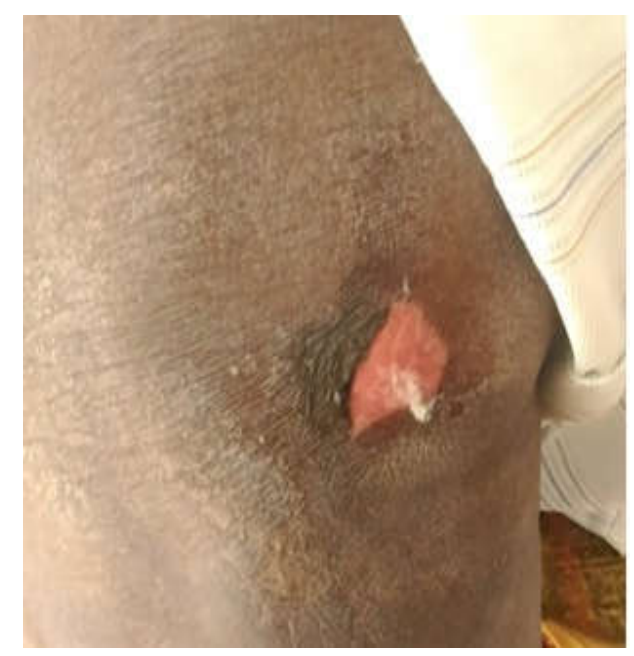

Fig 1: Lesions showing on back

Referral from a dermatologist confirmed the diagnosis of Toxic Epidermal Necrolysis. Phenytoin was immediately stopped. He was started on injection Dexamethasone 2cc IM
OD and Fusidic acid ointment and vitamins were given. The patient was referred to higher centers for further treatment of TEN.

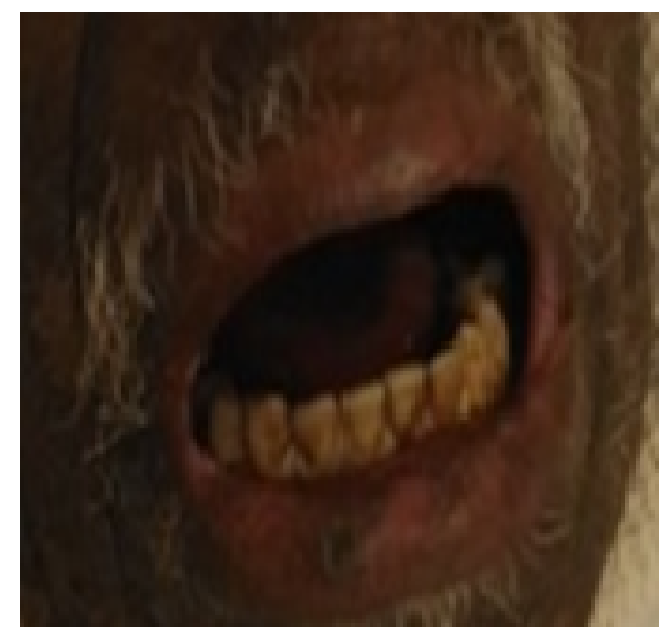

Fig 2: Erosions on oral cavity

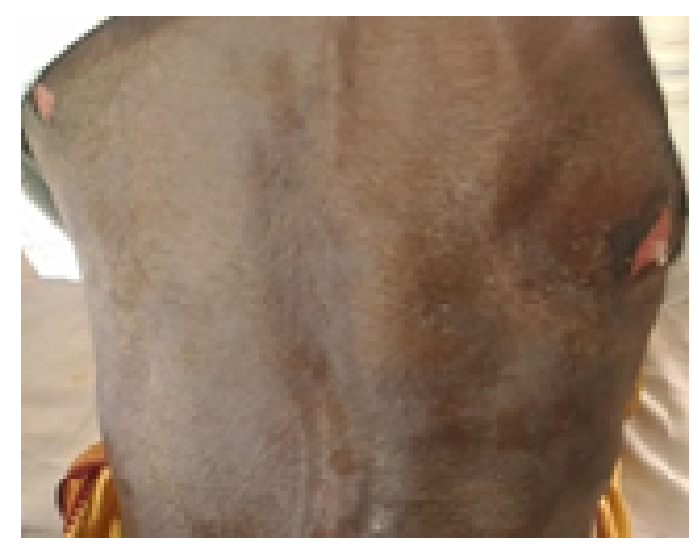

Fig 3: Erosions on back

\section{DISCUSSION}

TEN was first described by Lyell in 1956 [9]. SJS and TEN are characterized by fast increasing blistering exanthema of purpuric macules and target-like lesions accompanied by mucosal participation and skin detachments [10].

The main causative drugs that were accountable for causing mucocutaneous reactions like TEN, SJS and SJS/TEN are antimicrobials (37.27\%), anti-epileptics $(35.73 \%)$ and non-steroidal antiinflammatory drugs (15.93\%), Carbamazepine (18.25\%), Phenytoin (13.37\%), Fluoroquinolones (8.48\%) and Paracetamol (6.17\%) [11]. Carbamazepine 
(CBZ) and Phenytoin (PHT) are potent antiepileptic drugs causing cutaneous adverse reactions [12].

A multinational case-control study conducted in Europe between 1997 and 2001 confirmed burly relations between Phenytoin and other drugs with severe cutaneous adverse reactions like Stevens Johnson Syndrome and Toxic Epidermal Necrolysis [13].

An immune mechanism is concerned in the pathogenesis, but its nature is still indistinct. It is chiefly aimed at drug modified epidermal cells [14]. Different immune-inflammatory pathways with an early contribution of activated CD8 T-lymphocytes are concerned. Blister fluid contains extensively elevated levels of soluble interleukin- 2 receptors (sIL2R) possibly related to a local downregulation of an immune mediated cytotoxic reaction [15].

There is a prodormal phase in which there is burning sensation all over the skin and conjunctive, along with skin tenderness, fever, malaise and arthralgias. Fluid and protein loss occurs as in 2nd degree burns. The Nikolsky's sign is positive in erythematous skin. As a rule, oral, genital and anal mucous membranes are rigorously concerned. Nail shedding and hair loss may arise. Mucous membrane participation occurs in $85 \%-95 \%$ cases and precedes the skin contribution is seen in one third of cases [7].

This patient diagnosed with Phenytoin induced TEN. The dermatologist ordered to stop the prescribed drugs. Further complications include acute tubular necrosis, bronchopneumonia, membranous glomerulonephritis, hypovolemic shock, disseminated intravascular coagulation, gastrointestinal hemorrhage, anonychia, entropion, cicatricial alopecia, corneal opacities, ectropion can also occur.

Treatment is mainly supportive with elimination of the precipitating agent, maintaining fluid and temperature homeostasis, treating multi-organ damage, and preventing additional systemic complications [16]. A recent retrospective monocenter study suggests that a small course of high dose corticosteroids (dexamethasone) may be of benefit [17]. On the other hand, a recent retrospective casecontrol study conducted by Schneck et al. in France and Germany concluded that corticosteroids did not show a major effect on mortality in association with supportive care only [18]. Thalidomide, high dose intravenous immunoglobins, Cyclosporin, TNF antagonists, plasmapheresis/plasma exchange (PE) and Cyclophosphamide are used for treating this disease [19]. Topiramate or Levetiracetam (antiepileptic drugs) will be the treatment of choice for this patient when Phenytoin has induced TEN.

\section{DISCUSSION}

We present this case, for its rare occurrence, the drug Phenytoin involved in causing the toxic epidermal necrosis. Before starting treatment with anticonvulsants and other drugs, patients should be screened first, so that the medications which are potent to cause adverse drug reactions could be avoided so that further complications and mortality can be reduced.

\section{ACKNOWLEDGEMENT}

Authors are thankful to the Principal and Secretary, Vaagdevi college of Pharmacy, for providing necessary facilities and actions towards the fruitful completion of this research work.

\section{CONFLICT OF INTEREST}

The author(s) confirm that this article content has no conflict of interest. 


\section{REFERENCES}

[1] Valia AR, Valia RG. Vesiculobullous disorders. In: Valia AR, Valia RG, editors. IADVL Textbook and Atlas of Dermatology. 2nd ed. Mumbai : Bhalani Publishing House, 2001; 857-905.

[2] Lebargy F, Wolkenstein P, Gisselbrecht M et al. Pulmonary complications in toxic epidermal necrolysis: a prospective clinical study. Intensive Care Med 1997, 23:1237-44.

[3] Revuz J, Penso D, Roujeau JC et al. Toxic epidermal necrolysis. Clinical findings and prognosis factors in 87 patients. Arch Dermatol 1987, 123:1160-65.

[4] Maxine A. Papadakis MD, Stephen J. McPhee MD, Michael W. Rabow MD : Current medical diagnosis and treatment 55th edn 2016, 136.

[5] Wolkenstein P, Revuz J. Toxic epidermal necrolysis. Dermatol Clin. 2000;18:48595.

[6] Ghislain PD, Roujeau JC. Treatment of severe drug reactions: Stevens-Johnson syndrome, toxic epidermal necrolysis and hypersensitivity syndrome. Dermatol Online J. 2002;8:5.

[7] Roujeau JC, Chosidow O, Saiag P et al. Toxic epidermal necrolysis (Lyell syndrome). J Am Acad Dermatol. 1990;23:1039-58.

[8] Sharma VK, Sethuraman G, Minz A. Stevens Johnson syndrome, toxic epidermal necrolysis and SJS-TEN overlap: a retrospective study of causative drugs and clinical outcome. Indian J Dermatol Venereol Leprol. 2008; 74: 238-40.

[9] Hurwitz RM, Rivera HP, Gooch MH et al. Toxic shock syndrome or Toxic epidermal necrolysis? Case reports showing clinical
[10]

[11] similarity and histological seperation. J Am Acad Dermatol 1982, 7:246-54.

Roujeau JC. The spectrum of StevensJohnson syndrome and toxic epidermal necrolysis: a clinical classification. J Invest Dermatol 1994; 102:28S-30S.

Tejas K. Patel, Manish J. Bravaliaya, Dineshchandra Sharma et al. Systemic review of the drug-induced StevensJohnson syndrome and toxic epidermal necrolysis in Indian population. Indian Journal of Dermatology, Venerology, and Leprology. 2013; 379:89.

Arif H, Buchsbaum R, Weintraub D, Koyfman S, Salas-Humara C, Bazil CW, et al. Comparison and predictors of rash associated with 15 antiepileptic drugs. Neurology 2007; 68:1701-09.

Mockenhaupt $\mathrm{M}$ et al. Stevens-Johnson syndrome and toxic epidermal necrolysis: assessment of medication risks with emphasis on recently marketed drugs. J Invest Dermatol. 2008 Jan; 128(1):35- 44.

Roujeau JC, Chosidow O, Saiag P, et al. Toxic epidermal necrolysis (Lyell's syndrome). J Am Acad Dermatol 1990, 23: 1039-58.

Correia O, Delgado L, Roujeau JC, et al. Soluble interleukin 2 receptor and interleukin 1-alpha in Toxic epidermal necrolysis: a comparative analysis of serum and blister fluid samples. Arch Dermatol 2002, 138:29-32

Borchers, A.T., Lee, J.L., Naguwa, S.M., et al. Stevens-Johnson syndrome and toxic epidermal necrolysis. Autoimmun. Rev. 7, 2008, 598-605.

Kardaun SH, Jonkman MF: Dexamethasone pulse therapy for StevensJohnson syndrome/toxic 
epidermal necrolysis. Acta Derm Venereol 2007, 87:144-48.

[18] Schneck J, Fagot JP, Sekula P, et al. Effects of treatments on the mortality of StevensJohnson syndrome and toxic epidermal necrolysis: A retrospective study on patients included in the prospective
EuroSCAR Study. J Am Acad Dermatol 2008, 58:33-40

[19] Kokcam: toxic epidermal necrolysis probably due to cosmetic cream: a case report: Acta Dermatoven APA Vol 18, 2009.

\section{How to cite this article:}

Yaswanth Kumar K et al Phenytoin Induced Toxic Epidermal Necrolysis - A Case Report. Int. J. Adv. Pharm. Biotech., 2018; 4(4): $1-5$. 